\title{
Correlation between Histopathological Findings and Results of Direct Immunofluorescence in the Diagnosis of Canine Localized Cutaneous Chronic Lupus Erythematosus
}

\author{
Juliana Odaguiri', Valéria Aoki ${ }^{2}$, Lígia Maria Ichimura Fukumori' ${ }^{2}$, Alexandre Marques Périgo ${ }^{2}$, \\ Nilceo Scwery Michalany ${ }^{3}$, Isabella Fontana ${ }^{4} \&$ Carlos Eduardo Larsson ${ }^{1}$
}

\begin{abstract}
Background: Localized chronic cutaneous lupus erythematosus (CCLE), also known as discoid lupus erythematosus, is one of the most prevalent canine autoimmune skin diseases. Histopathology is considered the gold standard for the diagnosis of CCLE and the accuracy of which can be increased by use of direct immunofluorescence (DIF). This study aimed to investigate the fluorescence pattern revealed by DIF in cases of canine localized CCLE and to establish and compare its effectiveness with that obtained from histopathology.

Materials, Methods \& Results: Eleven dogs suspicious to localized CCLE, i.e., those animals that presented mucocutaneous lesions as erythema, leucoderma, erosive-ulcerative lesions, and loss of nasal planum architecture and its transition to the haired skin underwent medical physical and laboratory examinations (blood count, platelet count, determination of alanine transaminase, alkaline phosphatase, total protein, serum albumin, urea, creatinine). Only those animals that proved to be normal across both the physical and laboratorial evaluation were included in Group I. Animals belonging to this group were submitted to general anesthesia to biopsy two samples of lesioned skin from nasal planum to histopathologic examination and DIF test. Five dogs with no skin lesions were included in Group II as negative control to the DIF assay. Two samples of no lesioned skin from nasal planum were biopsied to histopathologic and DIF evaluation. The kappa $(k)$ coefficient was used to determine the degree of agreement and reliability of the results of both tests. A $P$-value $<5 \%$ was considered to be statistically significant. In Group I, all animals were normal across both the physical and laboratorial evaluation. A diagnosis of canine CCLE was established in 81.8\% (9/11) of the animals based on histopathology analysis. Two dogs, numbers 10 and 11, respectively, had histopathologic findings suggestive of cutaneous leishmaniasis and compatible with canine demodicosis. The DIF assay confirmed the diagnostic of canine CCLE in 100\% (11/11) of the cases, including dogs numbers 10 and 11. Direct immunofluorescence positivity for canine localized CCLE was determined by the presence of homogeneous green fluorescence in the basement membrane zone, with IgM and C3 immunoreagents being found at a significantly higher frequency $(P=0.007)$ than $\operatorname{IgA}$ and $\operatorname{IgG}(P=0.017$ and $P=0.037$, respectively). In Group II, no alterations from histopathologic examination and unspecific fluorescence from DIF reaction were shown in all animals belonging to this group. A substantial and significant degree of agreement or reliability $(k=0.738$ and $P=$ 0.002 , respectively) was established between the results of both tests.

Discussion: In veterinary medicine, there is a lack of studies about DIF around autoimmune dermatoses. This is the first manuscript comparing histopathological and direct immunofluorescence findings in the diagnostic of dogs with localized CCLE. In the present study, the positivity to the DIF assay for canine localized CCLE was established by the presence of green fluorescence of a homogeneous morphologic pattern, especially for IgM and C3, located in the BMZ and cutaneous annexes. Direct immunofluorescence excluded the suspicion of cutaneous leishmaniasis determined by the histopathological findings and confirmed the diagnostic of canine localized CCLE in the dog number 10. Statistically, a substantial degree of agreement and reliability was shown between DIF and histopathology. Therefore, we concluded that the DIF assay is a highly effective and useful complementary examination that improves our ability to diagnose canine CCLE.
\end{abstract}

Keywords: discoid lupus erythematosus, canine, cutaneous chronic lupus erythematosus, direct immunofluorescence. 


\section{INTRODUCTION}

Canine localized chronic cutaneous lupus erythematosus (CCLE) is one of the most prevalent autoimmune skin diseases in dogs. The most common cutaneous lesions are characterized by depigmentation, erythema, and scaling of the nose. A helpful early change is the conversion of the normally rough, cobblestone-like architecture of the nasal planum to a smooth surface $[2,5,6,8,14]$. Some authors consider the discoid lupus erythematosus (DLE) description inappropriate for dogs affected by the disease, because the cutaneous lesions do not acquire the morphologically discoid appearance found in human patients with the condition [2,11]. CCLE differs from systemic lupus erythematosus (SLE), in its absence of extra-mucocutaneous manifestations, which typically means that the prognosis is good $[5,6,14]$.

Diagnosis of canine localized CCLE is established based on the association of three diagnostic criteria, i.e., clinical, anatomic, and pathologic, and the absence of systemic manifestations of SLE. It is possible to improve our ability to diagnose CCLE using direct immunofluorescence (DIF), where it is possible to verify the presence of autoantibodies and complement activation along the dermal-epidermal junction, also known as the basement membrane zone (BMZ) [7,11]. Although DIF is not a routine diagnostic examination, it is indicated for at least $20 \%$ of suspected cases of CCLE in which gross pathology does not allow for a precise etiologic diagnosis [2]. The aim of the present study was to determine the fluorescence pattern in cases of canine CCLE, in addition to establishing and comparing the effectiveness of DIF with that of histopathology.

\section{MATERIALS AND METHODS}

\section{Animal recruitment and clinical management}

This study was approved under the Ethical Principles in Animal Research followed at the authors' institution and included companion dogs brought by their owners for treatment to either of two dermatology clinics in major veterinary centers in Brazil.

Eleven dogs with mucocutaneous lesions suggestive of CCLE, i.e., erythema, leucoderma, erosiveulcerative lesions, and loss of nasal planum architecture and its transition to the haired skin, underwent a medical history as well as physical and laboratory examinations (blood count, platelet count, determina- tion of alanine transaminase, alkaline phosphatase, total protein, serum albumin, urea, creatinine). Only animals that had not been treated with corticosteroids (topical or systemic) in the previous 60 days and had a normal physical examination and laboratory investigations were included in group 1. Biopsies of the lesions present on the nasal planum from dogs in this group were performed under general anesthesia. Two skin samples were collected from each animal for histopathologic analysis and DIF reaction.

Group 2 was a negative control for DIF reaction and contained five dogs with no skin alterations that had been euthanized due to senility or after car accidents. All animals were healthy and had not been treated with any medications according to their medical histories. Immediately after the animals were euthanized, two uninjured skin fragments were collected for histopathologic testing and DIF reaction.

\section{Biopsy of skin fragments for histopathology}

Skin fragments with leucodermic lesions, erythema, and loss of architecture in both the nasal planum and in its transition to the haired skin with diameters ranging from $3 \mathrm{~mm}$ to $4 \mathrm{~mm}$ were collected from the group 1 animals using a punch. Residual blood was removed from the biopsied samples, which were immediately stored in $10 \%$ formaldehyde. Histopathologic examination was performed in a specialized, private laboratory. The same procedure was carried out for the group 2 animals; however, healthy skin fragments were collected from the nasal planum.

\section{Biopsy of skin fragments for DIF and DIF reaction}

A skin fragment was collected from the nasal planum of each animal in group 1, with the same lesion characteristics as those previously mentioned, with the aid of the punch ( 3 and $4 \mathrm{~mm}$ ), for use in DIF. The samples were placed in Eppendorf tubes containing cryoprotective medium (Tissue-Tek O.C.T. Compound $\left.{ }^{\circledR}\right)^{1}$ and kept at a temperature of $-20^{\circ} \mathrm{C}$ for a maximum of 21 days. The DIF reaction was performed in the cutaneous immunopathology laboratory at our institution. The same procedure was employed for the animals of group 2, but using skin fragments devoid of nasal planum lesions.

Each skin fragment was cryosectioned at $-20^{\circ} \mathrm{C}$ and a thickness corresponding to four microns, and then arranged in quadruplicate on salinized slides. Four slides were prepared for each animal in order to 
evaluate, individually, the deposition of three different classes of immunoglobulins and a canine complement factor, respectively: $\operatorname{IgA}, \operatorname{IgG}, \operatorname{IgM}$, and $\mathrm{C}_{3}$. For each section, the primary anti-canine antibody conjugates were applied to fluorescein isothiocyanate (anti-IgA, anti-IgM and anti-C3, 1:40 dilution $\left(\text { Bethyl }^{\circledR}\right)^{2}$ and anti$\operatorname{IgG}\left(\text { Sigma }^{\circledR}\right)^{3}$ at 1:20 dilution in Evans blue dye, also at 1:20. The sections remained in their conjugates for $30 \mathrm{~min}$ in a dark, moist chamber at room temperature in order for the binding of the conjugates to the immunocomplexes to occur. Next, we performed a wash with Tris-buffered saline alkaline solution ( $\mathrm{pH}$ 7.5) for 20 min to achieve greater exposure of the antigenic sites. To complete the mounting of each section, a drop of buffered glycerin ( $\mathrm{pH}$ 9.0) was instilled over each slice of the fragment to augment the reaction's fluorescence. The preparation was covered with a cover slip and read under the epiluminescent microscope (model HBO $)^{4}$.

\section{Statistical analysis}

We determined the degree of agreement and reliability between the DIF results and those of histopathology, as well as the frequency of positivity to the immunoreagents (IgA, C3, IgM e IgG) in all the dogs with CCLE included in this study. Analysis of the data was performed using Statistical Package for the Social Sciences software (SPSS Inc., Chicago, IL, USA). For this, we used the Kappa $(k)$ coefficient, including the 16 animals gathered from groups 1 and 2, in order to determine the degree of agreement or reliability of the DIF results, when compared to histopathology, taking into consideration values between "negative 1" (complete disagreement) and "positive 1" (total agreement). For the results obtained, we considered a $P$-value of $<$ $5 \%$ to be statistically significant. Table 1 shows the $k$ values and their respective interpretations.

Table 1. Kappa agreement index.

\begin{tabular}{cc}
\hline Kappa $(k)$ values & Agreement \\
\hline$-1,0$ & None \\
$0-0.19$ & Insignificant \\
$0.20-0.39$ & Weak \\
$0.40-0.59$ & Moderate \\
$0.60-0.79$ & Substantial \\
$0.80-1.00$ & Perfect \\
\hline
\end{tabular}

RESULTS

All parameters evaluated by the physical and laboratory investigations (blood count, white blood cell count, platelet count, alanine transaminase, alkaline phosphatase, total protein, serum albumin, urea, creatinine, electrocardiography) were within normal range in all 11 dogs.

Histopathologic examination established the diagnosis of CCLE in $81.8 \%$ (9/11) of the animals in group 1. Varying degrees of vacuolar degeneration and a significant reduction of melanin in the keratinocytes were observed in the basal layer in all of the animals. Thickening and irregularity of the basal membrane was also a frequent histologic finding $(88.9 \% ; 8 / 9)$. In the papillary dermis, lymphoplasmacytic infiltrate, in most cases compromising the basal layer, and the presence of melanophages were the primary histologic alterations observed in this region. Periadnexal lymphocytic infiltrate could be observed in the reticular dermis (Figure 1).

Two dogs in group 1 had histopathologic findings suggestive of cutaneous leishmaniasis and compatible with canine demodicosis, respectively (Figures 2 and 3).

In dog 10, histopathologic examination raised suspicion for cutaneous leishmaniasis, so serological testing by indirect immunofluorescence and enzymelinked immunosorbent assay were performed. Additionally, parasitologic examination using material collected via aspiration puncture of the popliteal lymph nodes, and immunohistochemistry, were performed. All results were negative.

Histopathologic changes were not observed in the skin fragments collected from the nasal planum of the dogs included in group 2.

In group 1, DIF established the diagnosis of CCLE in $100 \%$ (11/11) of the animals, including in dogs number 10 and 11, who had initially presented a histopathologic diagnosis of cutaneous leishmaniasis and signs consistent with canine demodicosis, respectively. A positive reaction was characterized by a homogeneous fluorescent green band located in the BMZ (Figures 4 and 5). Distinct patterns (focal or continuous) and fluorescent intensity were observed (Table 2).

Different positivity frequencies were encountered for $\operatorname{IgA}(63.6 \%$; 7/11), $\operatorname{IgM}(72.7 \%$; 8/11), $\operatorname{IgG}(54.5 \%$; $6 / 11)$, and $\mathrm{C}_{3}(72.7 \% ; 8 / 11)$, as shown in Figure 6.

With the exception of $\operatorname{dogs} 2$ and 6, which showed positivity for only IgM and IgG, respectively, all the other dogs presented positive results in equal or greater numbers for the two immunoreagents.

In all cases, we observed the homogeneous fluorescence pattern in the BMZ, varying between focal and continuous. When observing positivity of the autoantibod- 
ies conjugated to fluorescein in the $\mathrm{BMZ}$ and periadnexal or perivascular regions, three different levels of fluorescent intensity were encountered (intense, moderate or weak) with their respective immunoreagents (Figure 7).

The five animals from group 2 did not demonstrate positivity for the DIF reaction.

Comparing the results of DIF with those of histopathology, we obtained an overall value of agreement or reliability of $81.8 \%(9 / 11)$ and a $k$-value of 0.738 , translating to an agreement or reliability classified as substantial and statistically significant $(P=0.002)$ between the two diagnostic methods.

In all of the animals diagnosed with canine CCLE by DIF, we observed positive fluorescence for $\mathrm{C} 3$ and $\operatorname{IgM}$ at a significantly higher frequency than for IgA and IgG (Table 3).

Table 2. Results of direct immunofluorescence in injured skin of 11 dogs with chronic cutaneous lupus erythematosus.

\begin{tabular}{|c|c|c|c|c|}
\hline Dog & Anti-IgA & Anti-C3 & Anti-IgM & Anti-IgG \\
\hline 1 & $\begin{array}{c}\text { BMZ: Moderate, } \\
\text { homogeneous and focal } \\
\text { fluorescence }\end{array}$ & $\begin{array}{l}\text { BMZ: Low, homogeneous and } \\
\text { focal fluorescence }\end{array}$ & Absence of specific fluorescence & Negative \\
\hline 2 & Negative & Negative & $\begin{array}{l}\text { BMZ: Moderate, homogeneous } \\
\text { and focal fluorescence. } \\
\text { Vessels of the papillary } \\
\text { dermis: moderate and granular } \\
\text { fluorescence }\end{array}$ & Negative \\
\hline 3 & Negative & Negative & $\begin{array}{l}\text { Periadnexal and perifollicular } \\
\text { regions: Moderate, } \\
\text { homogeneous and continuous } \\
\text { fluorescence }\end{array}$ & $\begin{array}{l}\text { BMZ, periadnexal and } \\
\text { perifollicular regions: } \\
\text { Moderate, homogeneous } \\
\text { and focal fluorescence }\end{array}$ \\
\hline 4 & $\begin{array}{c}\text { BMZ: Low, homogeneous } \\
\text { and continuous } \\
\text { fluorescence }\end{array}$ & $\begin{array}{l}\text { BMZ: Moderate, homogeneous } \\
\text { and focal fluorescence }\end{array}$ & Absence of specific fluorescence & $\begin{array}{l}\text { Absence of specific } \\
\text { fluorescence }\end{array}$ \\
\hline 5 & $\begin{array}{l}\text { BMZ: Low, homogeneous } \\
\text { and focal fluorescence }\end{array}$ & $\begin{array}{l}\text { BMZ: Low, homogeneous and } \\
\text { focal fluorescence }\end{array}$ & $\begin{array}{c}\text { BMZ and periadnexal: } \\
\text { Moderate, homogeneous and } \\
\text { focal fluorescence }\end{array}$ & $\begin{array}{l}\text { BMZ: Intense, } \\
\text { homogeneous and focal } \\
\text { fluorescence }\end{array}$ \\
\hline 6 & $\begin{array}{l}\text { Absence of specific } \\
\text { fluorescence }\end{array}$ & $\begin{array}{l}\text { Absence of specific } \\
\text { fluorescence }\end{array}$ & Absence of specific fluorescence & $\begin{array}{l}\text { BMZ: Moderate, } \\
\text { homogeneous and focal } \\
\text { fluorescence }\end{array}$ \\
\hline 7 & $\begin{array}{l}\text { BMZ: Low, homogeneous } \\
\text { and focal fluorescence }\end{array}$ & $\begin{array}{c}\text { BMZ and adnexal: Moderate, } \\
\text { homogeneous and continuous } \\
\text { fluorescence }\end{array}$ & $\begin{array}{c}\text { BMZ and adnexal: Moderate, } \\
\text { homogeneous and continuous } \\
\text { fluorescence }\end{array}$ & $\begin{array}{l}\text { Absence of specific } \\
\text { fluorescence }\end{array}$ \\
\hline 8 & $\begin{array}{c}\text { BMZ: Low, homogeneous } \\
\text { and continuous } \\
\text { fluorescence }\end{array}$ & $\begin{array}{l}\text { BMZ: Moderate, homogeneous } \\
\text { and continuous fluorescence }\end{array}$ & $\begin{array}{l}\text { BMZ: Moderate, homogeneous } \\
\text { and continuous fluorescence }\end{array}$ & $\begin{array}{l}\text { BMZ: Moderate, } \\
\text { homogeneous and focal } \\
\text { fluorescence }\end{array}$ \\
\hline 9 & $\begin{array}{c}\text { BMZ: Moderate, } \\
\text { homogeneous and focal } \\
\text { fluorescence }\end{array}$ & $\begin{array}{l}\text { BMZ and the vessel wall of } \\
\text { the papillary dermis: Intense, } \\
\text { homogeneous and continuous } \\
\text { fluorescence }\end{array}$ & $\begin{array}{c}\text { BMZ and adnexal: Moderate, } \\
\text { homogeneous and continuous } \\
\text { fluorescence }\end{array}$ & $\begin{array}{l}\text { Absence of specific } \\
\text { fluorescence }\end{array}$ \\
\hline 10 & $\begin{array}{c}\text { BMZ: Moderate, } \\
\text { homogeneous and } \\
\text { discontinuous fluorescence }\end{array}$ & $\begin{array}{l}\text { BMZ: Moderate, homogeneous } \\
\text { and continuous fluorescence }\end{array}$ & $\begin{array}{l}\text { BMZ: Moderate, homogeneous } \\
\text { and continuous fluorescence }\end{array}$ & $\begin{array}{l}\text { Focal fluorescence in } \\
\text { hair follicle }\end{array}$ \\
\hline 11 & $\begin{array}{l}\text { Absence of specific } \\
\text { fluorescence }\end{array}$ & $\begin{array}{l}\text { BMZ: Moderate homogeneous } \\
\text { and continuous fluorescence, }\end{array}$ & $\begin{array}{l}\text { BMZ: Moderate, homogeneous } \\
\text { and continuous fluorescence }\end{array}$ & $\begin{array}{c}\text { BMZ: Moderate, } \\
\text { homogeneous and } \\
\text { continuous fluorescence }\end{array}$ \\
\hline
\end{tabular}


J. Odaguiri, V. Aoki, L.M.I. Fukumori, et al. 2017. Correlation between Histopathological Findings and Results of Direct Immunofluorescence in the Diagnosis of Canine Localized Cutaneous...

Acta Scientiae Veterinariae.45: 1470.

Table 3. Values of kappa index ( $k$ ) used to evaluate the frequency of positivity of immunoreagents ( $\operatorname{IgA}, \operatorname{IgM}, \operatorname{IgG}$ and C3), correlated with direct immunofluorescence for the diagnosis of canine chronic cutaneous lupus erythematosus.

\begin{tabular}{cccc}
\hline Immunoreagent & DIF $(k)$ & $P$ - value & Positivity frequency \\
\hline IgA & 0.522 & 0.017 & Moderate \\
C3 & 0.625 & 0.007 & Substantial \\
IgM & 0.625 & 0.007 & \\
IgG & 0.429 & 0.037 & Moderate \\
\hline
\end{tabular}

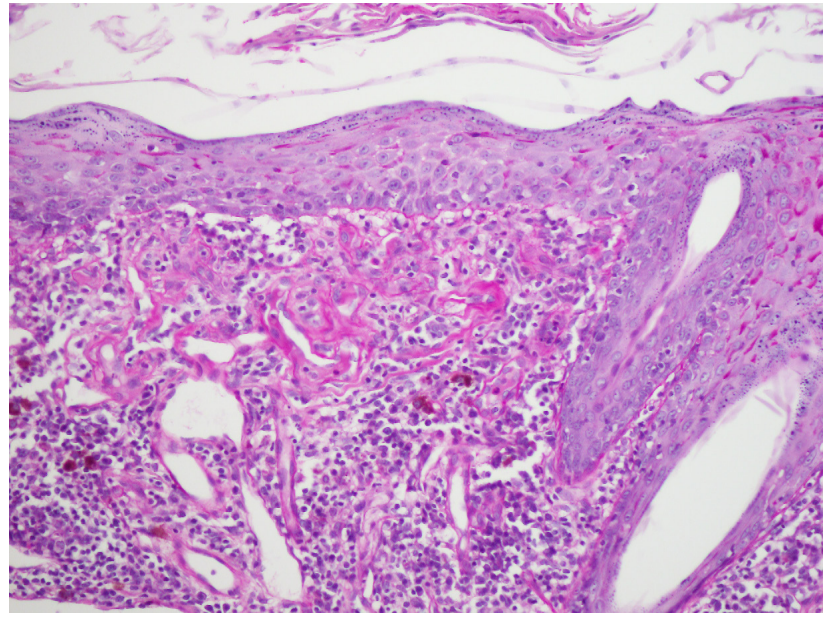

Figure 1. Vacuolar degeneration with reduction of the melanin pigment in keratinocytes of the basal layer. Basement membrane stained by periodic acid-Schiff, slightly and irregularly thickened. In papillary dermis and the superficial-vascular plexus, one can observe a moderate lymphocytic infiltrate attacking the basal layer and having interposed melanophages and some dilated blood vessels.

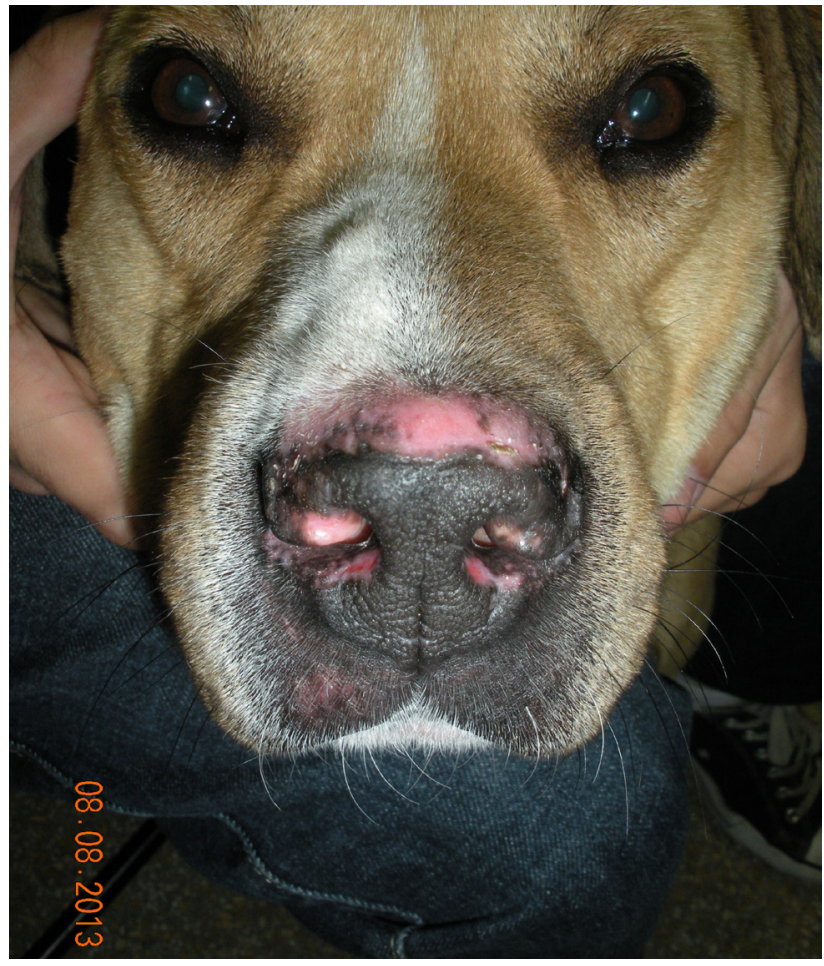

Figure 3. Dog 11, with erythematous lesions and loss of the nasal planum architecture with histopathologic diagnosis compatible with canine demodicosis.

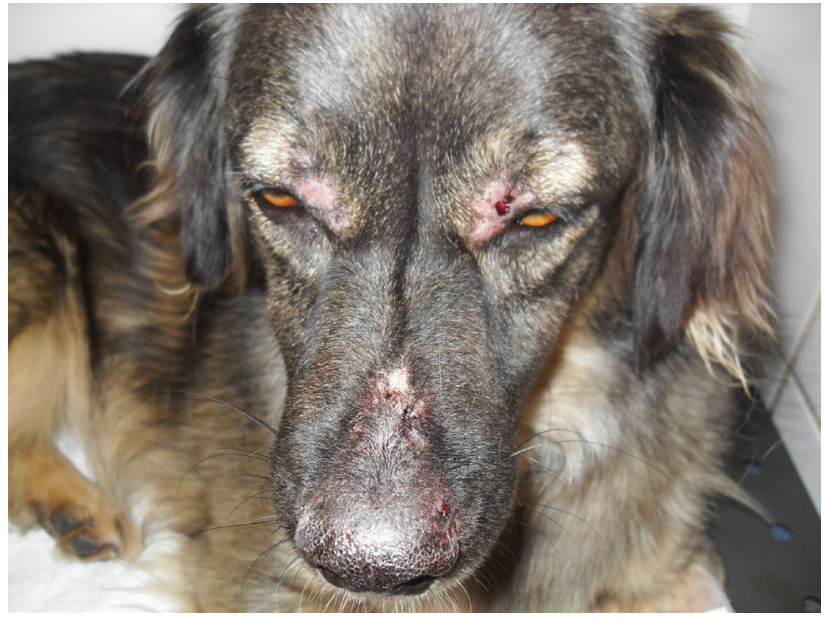

Figure 2. Dog 10, with alopecia and erythema on the nasal bridge and periocular region, and loss of the architecture of the nasal planum. Histopathologic diagnosis suggestive of cutaneous leishmaniasis.

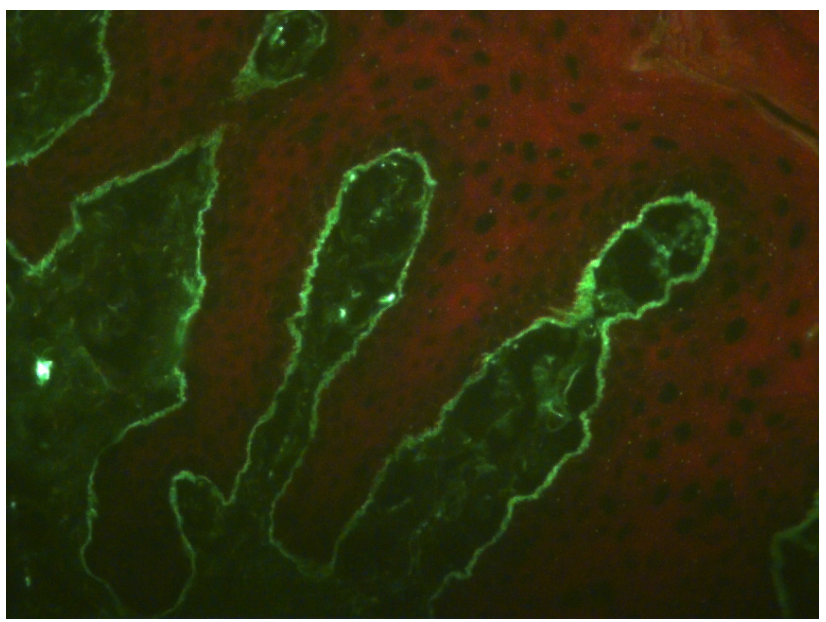

Figure 4. Intense, continuous and homogeneous fluorescence evidenced in the basement membrane zone, through assessment of the antic-C 3 complement in a dog with chronic cutaneous lupus erythematosus. Amplification 40x. Cutaneous Immunopathology Laboratory, Department of Dermatology, Faculty of Medicine, University of São Paulo, SP, Brazil. 


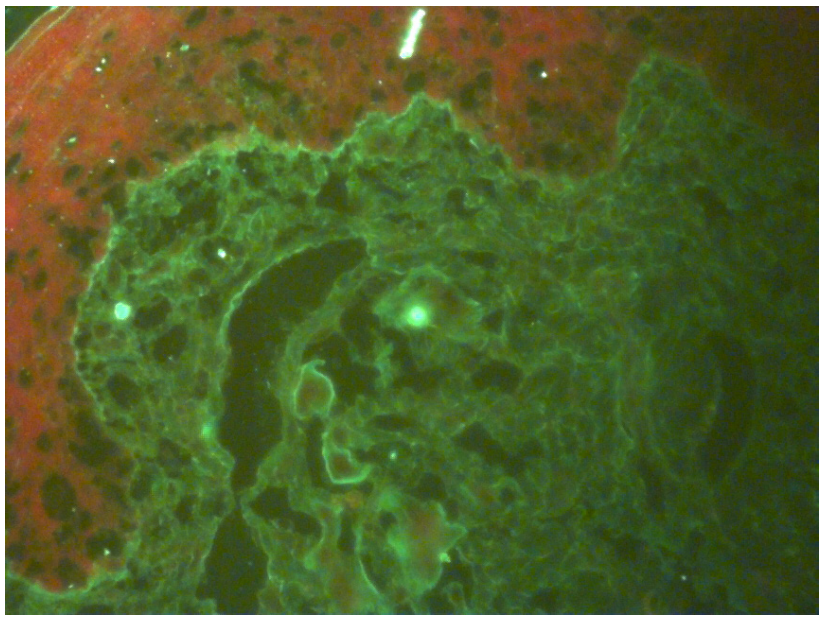

Figure 5. Low intensity, continuous and homogeneous fluorescence deposited at the basement membrane through assessment of presence of anti-IgA antibody, in a canine patient with chronic cutaneous lupus erythematosus. Amplification 40x. Cutaneous Immunopathology Laboratory, the Department of Dermatology, Faculty of Medicine, University of São Paulo, SP, Brazil.

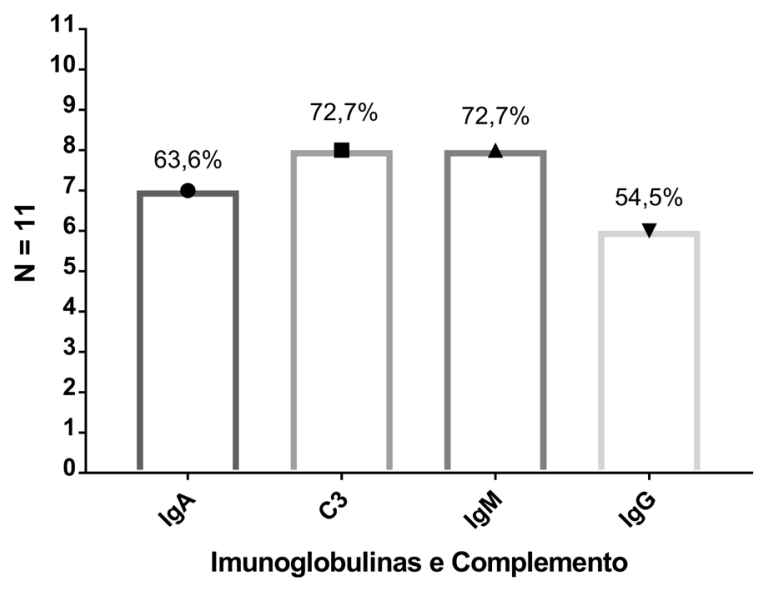

Figure 6. Direct immunofluorescence positivity for different classes of immunoglobulins and complement in $11 \mathrm{dogs}$ with chronic cutaneous lupus erythematosus.

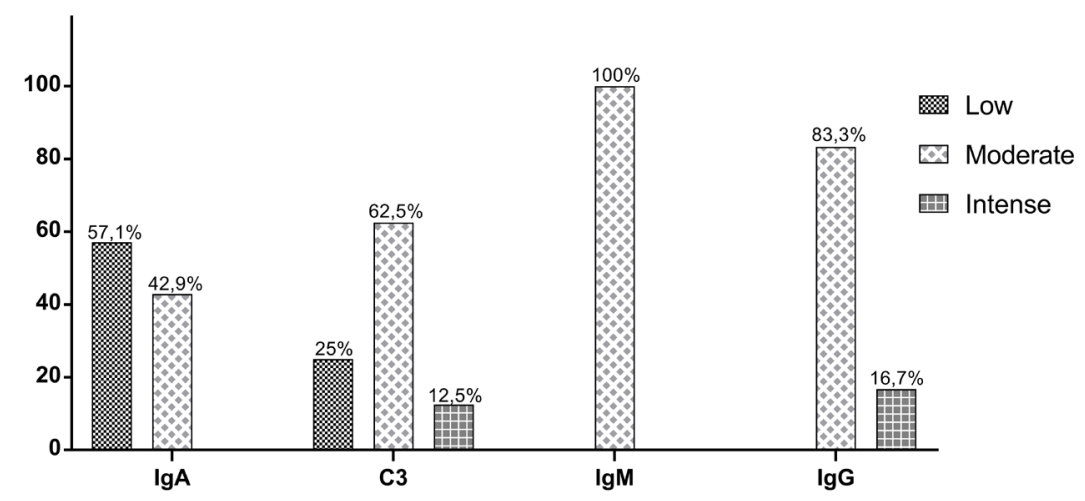

Figure 7. Different levels of fluorescence intensity (low, moderate and intense) from the direct immunofluorescence in $11 \mathrm{dogs}$ with chronic cutaneous lupus erythematosus.

\section{DISCUSSION}

CCLE is one of the most prevalent autoimmune skin diseases in dogs and, unlike SLE, does not cause multi-systemic clinical manifestations or changes in laboratory results $[6,8,14]$. Apart from the cutaneous lesions, all dogs in group 1 appeared healthy upon physical and laboratory examination, therefore excluding involvement of SLE.

The diagnosis of lupus erythematosus was confirmed based on histopathology in $81.8 \%$ of animals in group 1. In human medicine, it is known that histopathology alone can confirm the diagnosis in up to $92 \%$ of cases of CCLE [2]. There are no current comparable data available in the veterinary literature. The primary histopathologic changes observed in the group 1 dogs were degeneration or apoptosis of basal cells, a lymphocytic inflammatory infiltrate, and pigmentary incontinence resulting from loss of melanin caused by damage to keratinocytes in the basal layer and their phagocytosis by macrophages of the superficial dermis, all of which are considered to be the main histopathologic findings in canine CCLE [4].

Diagnosis of CCLE was established in 100\% of the animals in group 1 using DIF. This value exceeded the values reported in the literature, in which positivity ranges between $25 \%$ and $90 \%$ [8].

The morphologic pattern of fluorescence found in the BMZ was homogeneous. According to data originating from human dermatology, homogeneous and granular patterns, especially in deposits of $\operatorname{IgM}$ and $\mathrm{IgG}$, are the most frequently found patterns in CCLE $[1,10]$. 
The positivity frequencies of IgM $(72.7 \%)$ and $\mathrm{C} 3(72.7 \%)$ deposits found in the $\mathrm{BMZ}$ were significantly higher than those of IgA $(63.6 \%)$ and $\operatorname{IgG}$ $(54.5 \%)$. These values differ to some degree from the few reports already available in the veterinary literature, in which a greater positivity for $\operatorname{IgA}(70 \%)$ and $\mathrm{C}_{3}$ (90\%) and a lower positivity frequency for $\operatorname{IgM}(40 \%)$ and $\operatorname{IgG}(40 \%)$ have been established $[3,14]$.

Except for dogs 2 and 6, which were positive for only one immunoreagent, we obtained positive results in all other dogs for at least two immunoglobulins or in the complement. The DIF assay may be considered positive when there is at least one immunoreagent deposited in the $\mathrm{BMZ}$, and sometimes around the hair follicles. However, the specificity can be increased when two or more immunoreagents are shown in the dermo-epidermal junction of diseased skin [10-12]. Therefore, the DIF results for dog 10, that the initial histopathology of which was suggestive of cutaneous leishmaniasis, can be considered highly specific for CCLE, due to being positive for all four immunoreagents. It is known that the DIF reaction shows no fluorescence in cutaneous lesions caused by leishmaniasis [9]. A high incidence of false negative results can result from serological analysis, RIFI and enzyme-linked immunosorbent assay, given that seroconversion occurs in only $25 \%$ of dogs originating from endemic areas [13]. Further, parasitologic diagnosis, considered to be the gold standard for diagnosis of leishmaniasis, may not be sufficient to demonstrate the amastigote forms, especially in the absence of lymphadenopathy and anemia [8], as was the case in this dog. It is impossible to differentiate between CCLE and cutaneous leishmaniasis clinically. This is because the latter can have atypical clinical manifestations that mimic the classic lesions of other dermatopathies, which are referred to as pemphigus foliaceus-like, squamous cell carcinoma-like, alopecia areata-like and, also, CCLE-like [13]. Therefore, DIF was crucial for exclusion of the diagnosis of cutaneous leishmaniasis suggested by the histopathologic examination of this animal. Considering the above, the DIF assay can be considered decisive for exclusion of cutaneous leishmaniasis suggested by the histopathologic examination of this animal.

Similarly, the DIF results for animal number 11 were also highly specific for CCLE, due to their positivity for three immunoreagents, being able to attribute the finding of Demodex canis, a chance discovery of the mite, seeing as it is considered a normal component of the biota of dog skin.

Different levels of fluorescent intensity, i.e., weak, moderate or intense, were observed in the animals from group 1 .

To date, there are no studies, even in human medicine, that correlate the intensity of fluorescence found in the BMZ and cutaneous annexes with specific parameters, such as the severity or prognosis related to CCLE [1].

\section{CONCLUSIONS}

With the results obtained, we conclude that positivity to the DIF assay for canine CCLE is established by the presence of green fluorescence of a homogeneous morphologic pattern, especially for IgM and $\mathrm{C} 3$, located in the BMZ and cutaneous annexes. The substantial degree of agreement and reliability shown between DIF and histopathology indicate that the DIF assay is a useful and effective complementary examination for improvement of the diagnosis of canine CCLE.

\section{MANUFACTURERS}

${ }^{1}$ Sakura Finetek ${ }^{\circledR}$ USA Inc. Torrance, CA, USA.

${ }^{2}$ Bethyl Laboratories ${ }^{\circledR}$. Montgomery, TX, USA.

${ }^{3}$ Sigma-Aldrich ${ }^{\circledR}$. St Louis, MO, USA.

${ }^{4}$ Carl Zeiss AG. Oberkochen, Germany.

Ethical approval. The use of animals in this experiment was approved by the decision of the $\mathrm{n}^{\circ} 2433 / 2011$ - Comissão de Ética no Uso de Animais (CEUA/ FMVZ-USP).

Declaration of interest. The authors report no conflicts of interest. The authors alone are responsible for the content and writing paper.

\section{REFERENCES}

1 Aoki V., Sousa J.R., Fukumori L.M., Périgo A.M., Freitas E.L. \& Oliveira Z.N.P. 2010. Direct and indirect immunofluorescence. Anais Brasileiros de Dermatologia. 85: 490-500.

2 Duarte A.A. 2012. Lúpus eritematoso. In: Duarte A.A. (Ed). Colagenoses e a Dermatologia. 2.ed. Rio de Janeiro: Di Livros, pp.14-89. 
3 Goo M.J., Park J.K., Hong I.H., Yang H.J., Yuan D.W., Ki M.R., Han J.Y., Ji A.R., Kim T.H., Williams B.H. \& Jeong K.S. 2008. Discoid lupus erythematosus (DLE) in a Spitz Dog. The Journal of Veterinary. 70: 633-635.

4 Gross T.L., Ihrke P.J., Walder E.J. \& Affolter V.K. 2005. Skin Diseases of the Dog and Cat: Clinical and Histopathologic Diagnosis. Hoboken: Blackwell Science, 932p.

5 Larsson C.E. \& Lucas R. 2016. Tratado de Medicina Externa. São Caetano do Sul: Interbook, 853p.

6 Larsson C.E. \& Otsuka M. 2000. Lúpus eritematoso discoide - LED: Revisão e casuística em serviço especializado da Capital de São Paulo. Revista de Educação Continuada em Medicina Veterinária e Zootecnia. 3: 29-36.

7 Mehta V., Sarda A. \& Balachandran C. 2010. Lupus band test. Indian Journal of Dermatology, Venereology and Leprology. 76: 298-300.

8 Miller W.H., Griffin C.E. \& Campbell K.L. 2013. Autoimmune and immune-mediated dermatoses. In: Halliwell R.E.W. (Ed). Muller and Kirk's Small Animal Dermatology. 7th edn. St. Louis: Saunders, pp.432-500.

9 Minz R.W., Chabra S., Singh S., Radotra B.D. \& Kumar B. 2010. Direct immunofluorescence of skin biopsy: Perspective of an immunopathologist. Indian Journal of Dermatology, Venereology and Leprology. 76: 150-157.

10 Morrison L.H. 1999. When to request immunofluorescence: Practical hints. Seminars in Cutaneous Medicine and Surgery.18: 36-42.

11 Oberkirchner U., Linder K.E. \& Olivry T. 2011. Successful treatment of a novel generalized variant of canine discoid lupus erythematosus with oral hydroxychloroquine. Veterinary Dermatology. 23: 65-e16.

12 Ramos-e-Silva M. \& Castro M.C.R. 2009. In: Freitas T.H.P. \& Ribeiro A.E. (Eds). Fundamentos de Dermatologia. Lúpus Eritematoso. 2.ed. Rio de Janeiro: Atheneu, pp.1225-1254.

13 Roura X., Fondati A., Lubas G., Grandoni L., Maroli M., Oliva G., Paltrinieri S., Zatelli A. \& Zini E. 2013. Prognosis and monitoring of leishmaniasis in dogs: a working group report. Veterinary Journal. 198: 43-47.

14 Scott D.W., Miller W.H. \& Griffin C.E. 1996. Dermatologia de Pequenos Animais. Rio de Janeiro: Interlivros, 1130p. 